\title{
UNA REALIDAD EN EDUCACIÓN A DISTANCIA EN BRASIL: UNA EX- PERIENCIA EN LA FORMACIÓN DE PROFESORES
}

\section{(A REALITY IN DISTANCE EDUCATION IN BRAZIL: AN EXPERIENCE IN THE FORMATION OF PROFESORS)}

\author{
Sandra Regina dos Reis Rampazzo \\ Samira Fayez Kfouri \\ Aparecida Theodora Gozo \\ Universidade Norte do Paraná (Brasil)
}

\begin{abstract}
“As perspectivas da Educação à Distância estão nas mãos dos que se dispuserem a fazêla, com seriedade e comprometimento ético, garantindo suas condições de êxito"

(Lobo Neto, 1998, fls.4).
\end{abstract}

\section{RESUMEN}

Este artículo tiene como objetivo presentar la estructura de un curso de graduación a distancia, así como tejer consideraciones sobre el mismo a luz de los referenciales teóricos y, bajo la óptica de la vivencia real de los autores en dos años de curso en el ámbito del Sistema de Enseño Presencial Conectado da Universidad Norte del Paraná - UNOPAR. De esa manera, tomando como base esa realidad, este texto pretende contribuir para ensanchar la comprensión de la complejidad de la estructuración de cursos de formación de profesores, considerando la necesidad de promover innovaciones en este campo, con vistas a la calidad de la formación en cuestión y la democratización de la enseñanza.

\begin{abstract}
This article has as objective to present the structure of a course of long-distance graduation, as well as weaving considerations on the same to the light of theoretical referentials and, low to the optics of the real experience of the authors in the years of course in the scope of the System of Actual Education Connected of the North of Paraná University - UNOPAR. In this way, taking as base this reality, this text intends to contribute to increase the understanding of the complexity of the structure of courses of formation of teachers, being considered the necessity to promote innovations in this field, with sight in the quality of the formation in question and the democratization of the education.
\end{abstract}




\section{INTRODUÇÃO}

Este artigo tem por objetivo apresentar a estrutura de um curso de graduação a distância - o curso normal superior - um sonho que se tornou realidade para um grande contingente de cidadãos brasileiros, sem oportunidade de acesso ao ensino superior. O artigo permite, ainda, tecer considerações sobre a implementação do mesmo à luz dos referenciais teóricos da Educação a Distância (EAD) e da vivência prática cotidiana dos autores, no âmbito do Sistema de Ensino Presencial Conectado (SPEC) da Universidade Norte do Paraná (UNOPAR).

A EAD compõe oficialmente o cenário político educacional brasileiro, somente a partir de 1996, com a criação da Secretaria de Educação a Distância (SEED), como órgão do MEC apresentando "a clara intenção do atual governo de investir na educação a distância e nas novas tecnologias como uma das estratégias para democratizar e elevar o padrão de qualidade da educação brasileira" (Brasil, MEC, 2004, p.1).

Desde então, a EAD no Brasil vem crescendo aceleradamente, sob a égide da bandeira da democratização do ensino, "como estratégia de ampliação das possibilidades de acesso à educação", devendo aprofundar o compromisso de projetos pedagógicos inclusivos com os projetos histórico, político e cultural de uma sociedade, como preconiza Lobo Neto (2004, p.4). Porém, deve-se ter o cuidado de não tomá-la como panacéia da educação, nem tampouco como uma educação de segunda classe, destinada aos que não puderam realizar a educação no seu período regular.

Um passeio pelo histórico da EAD no âmbito internacional e no Brasil conduz à constatação da sua proximidade com a história da educação e da comunicação. Adotou-se uma diversidade de modelos que evoluíram com a própria história da humanidade. Da primeira geração de EAD, chamada de ensino por correspondência que, segundo Nipper (1989, apud Sammons, 2003), era baseada somente em material impresso, passando à incorporação das modernas tecnologias de informação e comunicação (TIC) - terceira e quarta geração de EAD, com o advento da Internet - , assistimos hoje à convivência com modelos que agregam simultaneamente as quatro gerações de $\mathrm{EAD}$.

A evolução da EAD tem trazido ao cenário educacional mudanças significativas. Da mesma forma, os programas atuais têm como principal alvo, os cursos voltados à valorização, qualificação e atualização do magistério. Porém, é necessário considerar que, conforme afirma Lobo Neto (1998), o que constitui as condições de êxito de um programa de EAD é o planejamento, a execução e a avaliação, sendo pensado, estudado e proposto com base em referenciais teóricos próprios da área.

Tomando por base essa realidade, este texto pretende contribuir para alargar a compreensão da complexidade da estruturação de cursos voltados à formação de professores, considerando a necessidade de promover inovações, neste campo, e 
tendo em vista a qualidade da formação em questão e a democratização do ensino, no Brasil.

O texto desenrola-se em três momentos, apresentando primeiramente as reflexões sobre o processo de construção de um curso de formação de professores em nível superior, passando pela demonstração da estrutura do curso e, por fim, tecendo considerações acerca da sua operacionalização, ressaltando os desafios presentes no fazer cotidiano, sob a ótica da vivência real dos autores, em dois anos e meio de funcionamento do curso.

\section{O PROCESSO DE CONSTRUÇÃO DE UM CURSO DE FORMAÇÃO DE PROFESSORES EM NÍVEL SUPERIOR}

As bases para a formação do professor dos anos iniciais do ensino fundamental, no Brasil, estabelecem novos rumos para os profissionais e para sua formação, exigindo um perfil reflexivo, que domine as tecnologias de comunicação e informação, voltado ao trabalho em equipe, preocupado com o processo de construção do conhecimento e inserido na luta pela democratização do ensino. Atendendo a esses princípios, a Universidade Norte do Paraná (UNOPAR), através de seu sistema proprietário de Ensino Presencial Conectado, criou o Curso Normal Superior Presencial Conectado (CNSPC), com habilitação para os anos iniciais, desenvolvido na modalidade à distância.

Visando sistematizar um curso que possibilitasse formar educadores altamente capacitados, a proposta pedagógica do curso da UNOPAR preocupou-se em propor e desenvolver ações que contemplassem novas perspectivas e possibilidades para a formação do educador do novo milênio. Partindo da realidade atual e compreendendo a necessidade de formar profissionais da educação alicerçados no ensino e na pesquisa, buscou proporcionar formação de qualidade em nível superior, direcionada a uma clientela bastante heterogênea, considerando a dimensão continental do país, uma vez que o curso poderia ser ofertado a todos os profissionais interessados independente da sua localização geográfica.

Assim, procurou-se desenvolver um curso fundamentado na legislação atual, contemplando a Lei de Diretrizes e Bases da Educação Nacional (LDBEN) no 9394/ 96, (Brasil..., 1996) particularmente o Artigo 62, regulamentado pelo Parecer no 01/99, que cria o Curso Normal Superior para formação do professor para os anos inicias do ensino fundamental, e o Artigo 80 que versa sobre a modalidade de ensino, presencial ou a distância e estabelece que cabe ao poder público incentivar o desenvolvimento e a veiculação do ensino a distância.

Partindo da legislação que define as diretrizes curriculares para formação do professor para atuação na educação básica e tomando por base os princípios da educação a distância, o CNSPC foi estruturado com carga de 2.800 horas, divididas em três anos letivos, sendo composto de 1.800 (mil e oitocentas) horas de conteúdos curriculares, 400 (quatrocentas) horas de práticas curriculares, 400 (quatro- 
centas) horas de estágio supervisionado e 200 (duzentas) horas de atividades acadêmico-científico-cultural.

Assim organizado, o curso visa formar o professor, como profissional da educação, apoiado na docência e tendo como princípios norteadores a sólida formação teórica e interdisciplinar, a unidade teoria/prática, a gestão democrática, o compromisso social e político do profissional da educação, o trabalho coletivo e interdisciplinar e a formação inicial articulada à formação continuada. Com base nestes princípios, pretende oferecer formação teórica e prática com vistas ao favorecimento da reflexão contextualizada dos problemas do sistema de ensino e da escola, apontando possibilidades inovadoras para a atuação do profissional da educação em seu campo de trabalho.

O CNSPC tem como eixo norteador a prática educativa pautada na relação entre teoria e prática nos espaços educativos e como finalidade de formar profissionais habilitados a atuar no ensino, na organização, na elaboração de projetos educacionais e na produção e difusão do conhecimento. Objetiva capacitar profissionais para atuar na docência, no planejamento e na gestão educacional do ensino fundamental dos anos iniciais, e profissionais para atuar, também, na organização de sistemas, de unidades, de projetos e experiências educacionais formais e nãoformais. Esmera-se em dar uma formação que supere a tradição pedagógica tecnicista, abrindo para a educação novas leituras teóricas, novos enfoques metodológicos e tecnológicos com o fim de conduzir o enfrentamento dos desafios de pesquisar o cotidiano escolar no contexto da complexa trama das relações sociais.

Visa ainda, proporcionar uma formação específica ao professor, profissional da educação, gestor da atividade docente, articulador da organização do trabalho pedagógico nos anos iniciais do ensino fundamental, articulador da dimensão interdisciplinar das áreas do conhecimento, de modo que ele se capacite a atuar crítica e interdisciplinarmente na realidade com visão sistêmica do espaço institucional de ensino e das organizações sociais, no planejamento, na gestão e na pesquisa do processo educativo. Requer a participação do professor no trabalho com pesquisa, integrada à investigação da realidade, reconhecendo que o papel do professor consiste em desenvolver suas funções como agente transformador da realidade.

A pesquisa é, dessa forma, elemento essencial e integrador do currículo. O curso visa, portanto, formar um profissional pesquisador para que inclua a investigação em sua prática diária, voltada para si mesmo na produção e socialização do conhecimento pedagógico, de modo sistemático. Requer a disponibilização de um espaço de construção coletiva, onde se insira o professor reflexivo que investiga, reflete, seleciona, planeja, organiza, integra, avalia, articula experiências, cria e recria formas de intervenção didática junto aos seus alunos para que estes avancem em sua aprendizagem, conforme preconiza o Parecer 009/2001 do CNE/CP (Brasil..., 2001). 
A proposta pedagógica do curso considera a continuidade no aprendizado e a auto-educação permanente como desafios postos ao professor. Fundamenta-se na construção estruturada do planejamento educacional comprometido com o processo do conhecimento e com as necessidades sociais, apoiado na compreensão da gestão democrática da escola, na democratização do ensino, na construção coletiva do projeto político pedagógico e na construção da autonomia da escola. A gestão da educação, hoje, só poderá acontecer com a efetiva participação de todos os profissionais responsáveis pelos espaços educativos e pelo ensino. Preocupa-se, ainda, com o desenvolvimento de capacidades e habilidades, tais como: especificação de conceitos, exposição de idéias, debate e diálogo (UNOPAR, 2003).

Busca formar o professor pesquisador e reflexivo, como sujeito do seu próprio processo de formação e construtor do projeto político-pedagógico do seu espaço de atuação, na aquisição de um conjunto de competências; e faculta a construção de uma prática pedagógica reflexiva dirigida à universalidade e interdisciplinaridade. Propicia a formação de um professor agente da transformação social preparado para a efetivação do exercício da cidadania, com autonomia no pensar, no sentir e no agir (UNOPAR, 2003).

Atende, assim, aos princípios filosóficos da liberdade de expressão e de pensamento baseados nos ideais de liberdade, coletividade e solidariedade humana necessários à formação do sujeito sociopolítico capaz de intervir no processo de construção histórica.

\section{ESTRUTURA DO CURSO NORMAL SUPERIOR PRESENCIAL CONEC- TADO}

Tomando por base os pressupostos explicitados, a UNOPAR criou o CNSPC estruturado mediante o Sistema de Ensino Presencial Conectado (SEPC) ofertando ensino a distância com qualidade àqueles que encontram dificuldades na participação presencial intensa. Para seu funcionamento, conta com uma equipe multidisciplinar de profissionais, composta por pedagogos, profissionais das diferentes áreas tecnológicas, técnicos em informática, professores, tutores, profissionais especializados na produção de material didático e de teleaulas, equipe de geração, entre outros.

A equipe pedagógica do CNSPC é composta pelos seguintes profissionais da educação:

- Pedagogos com titulação mínima de mestre, que atuem nos diferentes setores administrativos, destacando-se: na coordenação do curso - professor responsável pela integração dos princípios teóricos, metodológicos e epistemológicos da educação a distância no projeto pedagógico do curso, bem como pelo acompanhamento pedagógico do material didático impresso, pela seleção e treinamento de professores; na divisão de planejamento - professor responsável pela assessoria na elaboração e no acompanhamento da pro- 
dução das aulas e das atividades do curso; e, na divisão de tutoria - professor responsável por todo processo de envolvimento de tutores do curso;

- Professores especialistas: responsáveis pelas teleaulas, pelo conteúdo do material do caderno de estudos e pela orientação do Trabalho da Conclusão de Curso (TCC);

- Tutores eletrônicos: responsáveis pela coordenação e supervisão das atividades realizadas nas salas de recepção, orientando os tutores de sala e o supervisor de estágio na condução das atividades, nos procedimentos de avaliação da aprendizagem, no encaminhamento e acompanhamento do estágio supervisionado e nas práticas pedagógicas e em outras necessidades pedagógicas propostas pelo tutor de sala e pelos alunos;

- Tutor de sala: responsável pela tutoria nos locais de recepção, pelo assessoramento ao aluno, pelo encaminhando de dúvidas, por sugestões, comentários e participações dos alunos. É o tutor de sala o elo de ligação entre o aluno e a universidade nas questões acadêmicas e pedagógicas; e

- Supervisor de estágio: com a função de orientar, acompanhar e avaliar o aluno nas atividades de estágio supervisionado.

O curso está estruturado na modalidade bimodal, com teleaula através de videoconferência, atividades tutoriais, estudos independentes, estágios e práticas curriculares e trabalho de conclusão de curso, com atividades presenciais e a distância.

As videoconferências são geradas nos estúdios de TV, unidade do SEPC e veiculadas ao vivo, em canal fechado, através de satélite, simultaneamente para salas de recepção em todo o país. Estas teleaulas são planejadas por professores especialistas, com assessoria de uma equipe de planejamento especializada, que os auxilie durante a produção da aula.

Durante a apresentação das tele-aulas, são colocados à disposição do aluno, pela mediação do tutor de sala que se mantém na direção do uso dos recursos, o microfone e o chat da aula. Este chat é coordenado por um tutor especialista dentro do estúdio de geração, possibilitando a interatividade em tempo real entre alunos e professor. As teleaulas e o chat das aulas atividades são acompanhados, simultaneamente, por tutores eletrônicos, no intuito de fundamentar as orientações para o tutor de sala, com vistas a atender às solicitações dos alunos. Os chats possibilitam a participação dos alunos, principalmente no esclarecimento de dúvidas pontuais e na reposta a perguntas e comentários. Nas salas de recepção, o chat é coordenado pelo tutor de sala.

Cada teleaula é acompanhada de uma atividade, podendo esta aula-atividade, como é denominada, ser desenvolvida antes ou após a teleaula. Constitui-se de uma aula planejada pelo professor especialista e enviada previamente aos alunos, com atividades de reflexão e discussão dos conteúdos do tema. Sua realização é monitorada pelo tutor de sala, supervisionada pelos tutores eletrônicos e acompanhada pelo professor especialista, através de um chat específico no qual os alunos têm a 
oportunidade de expor idéias, tirar dúvidas e debater o assunto diretamente com o professor.

Além das atividades presenciais, cumpridas nas telessalas, o aluno realiza, a distância, atividades de estudo independente, configurado como auto-estudo, sendo o contato com os tutores eletrônicos possibilitado e incentivado sempre que necessário, e realizado a critério do aluno após o contato com o próprio tutor eletrônico, o que representa um estímulo à autonomia do aluno para a aprendizagem independente ou aprendizagem auto-dirigida que, segundo Garrison (1992), pode se referir a uma busca independente de aprendizagem, a uma maneira própria de organizar instrução, ou ainda a um atributo pessoal. Estas atividades são organizadas por eixo temático, pelo grupo de professores especialistas responsáveis pelos temas dos eixos.

Complementando o estudo, o aluno cumpre estágio supervisionado acompanhado por um supervisor, assim como atividades de práticas pedagógicas. A carga horária do curso se completa com atividades científico-culturais, tanto no âmbito de sua própria comunidade como fora de sua instituição.

Para atender as especificidades de um modelo pedagógico dessa envergadura, o curso apresenta uma proposta pedagógica inovadora, estruturada em sete eixos temáticos que se articulam, proporcionando o arcabouço teórico necessário à formação do professor para atuação na educação básica. Os eixos são distribuídos em seis módulos, com duração de um semestre cada um, perfazendo três anos letivos.

Os módulos abrangem uma dimensão formativa humana e específica. Os três primeiros módulos são voltados à formação do professor, ser humano, cidadão e profissional, que atua na formação de pessoas. Contemplam um núcleo de conhecimentos epistemológicos de saberes que permeiam a construção da educação e da cultura humana. Os três módulos subseqüentes abrangem os conhecimentos necessários ao profissional, e compreendem os fundamentos, as metodologias e as técnicas que instrumentalizam a formação específica e a atuação do profissional da educação no contexto escolar.

A pesquisa é o eixo articulador do curso e perpassa todos os módulos. Os momentos de estudo, produção de conhecimentos e reflexão consolidam-se na elaboração final do TCC. Este se desenrola num movimento espiralado, do início ao fim do curso e completa-se durante o percurso com uma vasta onda de novos saberes. O TCC reflete as análises, reflexões, estudos e ações realizadas durante os módulos, convergindo para a investigação científica de um tema originado da própria realidade. O tema do TCC emerge dos estágios e práticas curriculares, e é fundamentado pelos estudos teóricos.

O estágio curricular, atividade obrigatória do curso, constitui-se na reflexão e na ação, isto é, na prática escolar teórica. Proporciona a vivência de situações de ensino e aprendizagem, configurando um momento privilegiado de reflexão sobre a 
realidade escolar que possibilita a compreensão das determinantes que a influenciam. Encarado dessa forma, torna-se condição essencial para o pensar e o realizar a intervenção prática na organização escolar, contemplando sua gestão política, administrativa e pedagógica. Valoriza a relação entre teoria e prática e a produção de conhecimentos, com a finalidade de articular estudos teóricos e práticos direcionados ao desenvolvimento de competências, habilidades e atitudes necessárias ao professor para sua atuação nos anos iniciais. O estágio curricular está estruturado a partir do terceiro módulo e é acompanhado por um supervisor de estágio.

Com o fim de atender aos princípios do curso, foi desenvolvido um sistema de avaliação coerente com as inovações propostas, que respeitasse a legislação vigente bem como os pressupostos conceituais e os fundamentos da EAD. Assim, a avaliação é organizada de forma contínua e formativa, contemplando mais enfaticamente os aspectos qualitativos. Durante os módulos, são realizados trabalhos, organizados por eixo temático, constituindo estes o portfólio do módulo. Os trabalhos são elaborados pelo grupo de professores especialistas responsáveis pelo eixo temático e disponibilizados aos alunos eletronicamente. Durante o período de vigência da atividade, o aluno pode realizar solicitações junto ao tutor de sala, ao orientador e ao tutor eletrônico.

Além do portfólio, é realizada, durante o módulo, uma prova cumulativa interdisciplinar (PCI). Sua aplicação é feita de forma presencial, atendendo-se aos preceitos da legislação, e simultânea, em todas as unidades de recepção, sob o acompanhamento do tutor de sala, e a supervisão da equipe pedagógica. A organização permanece ao encargo de uma equipe de especialistas, sendo as questões elaboradas pelos professores especialistas, que se esmeram na interdisciplinaridade ao contemplar os temas trabalhados.

Considerando-se o desenho pedagógico e a necessidade de aferição de valor do processo avaliativo, foi desenvolvido para o curso, um modelo de verificação dos resultados expressos em conceitos, que superasse a prática tradicional de atribuição de notas. Esse modelo aplica-se a todas as atividades avaliativas, nas quais primou-se pelo aspecto interdisciplinar que envolve o processo de ensino e aprendizagem e a flexibilização do parâmetro numérico. Assim, a conceituação varia de insuficiente a excelente, sendo necessário, para aprovação, o conceito mínimo de suficiente.

No intuito de atender ao aluno nos mais variados aspectos, o curso conta com o recurso da Biblioteca Digital que captura, gerencia, armazena objetos digitais, procede a sua busca e possibilita o acesso a eles, dentro dos preceitos legais vigentes de tratamento relacionados aos direitos autorais sobre os objetos digitais, disponibilizando-os para a comunidade usuária do sistema. Além dos recursos informacionais disponibilizados pela Biblioteca Digital, o aluno tem acesso físico a uma bibliografia básica do curso, em sua unidade, bem como a disponibilização das tele-aulas, das sugestões de atividades complementares, de bibliografias complementares e de ori- 
entações prévias dos professores especialistas. Todos esses recursos podem ser disponibilizados e visualizados pelo aluno, no sistema, a qualquer momento do curso.

Contemplando uma estrutura plantada em uma moderna tecnologia, o projeto pedagógico do curso foi desenvolvido em sete eixos temáticos que formam os seis módulos, sendo estes constituídos de uma composição temática que abrange a formação geral do professor, necessária à atuação nos anos iniciais. Dessa forma, atendem à seguinte organização:

MÓDULO 1 - é composto por três eixos temáticos: Linguagens e Novas Tecnologias em Sistemas Educativos, Fundamentos Sociocultural-Político-Econômico do Processo Educativo e de Espaços Educativos e Contexto Brasileiro. Nesse módulo são tratadas as linguagens da comunicação e da tecnologia, buscando-se a compreensão das relações e das interações humanas que se dão nos espaços educativos. Também são apresentados os fundamentos que advêm das teorias evolutivas do conhecimento humano nas dimensões filosófica, sociológica, política, histórica e psicológica, com vistas a formar o professor para a compreensão e a habilidade de gerir o entendimento sobre os espaços educativos e os valores éticos, morais e sociais, no contexto brasileiro. Visa a formar competências e habilidades expressas na compreensão das linguagens como meio de comunicação humana, salientando o uso dos recursos de multimeios presentes na sociedade atual. A consolidação das competências e habilidades efetiva-se na prática pedagógica durante a execução do módulo.

MÓDULO 2 - contempla os seguintes eixos temáticos: Linguagens e Novas Tecnologias em Sistemas Educativos; Fundamentos Sociocultural-PolíticoEconômico do Processo Educativo; Espaços Educativos e o Contexto Brasileiro; A Criança, o Espaço Educativo e a ação Docente, de Pesquisa e de Formação na Ação Docente. O estudo dos temas desenvolvido no segundo módulo busca aprofundar a construção epistemológica do conhecimento sobre a humanidade, a formação da sociedade e seus reflexos nos espaços educativos. O processo e os espaços educativos começam a ser (re) definidos a partir de uma visão crítica, e culmina com o processo de construção da ação mediadora e da identidade dos envolvidos e no processo educativo, delineada pela compreensão da criança, dos espaços educativos e da ação docente. A pesquisa, ressaltando sua modalidade qualitativa, inicia uma ação reflexiva que se estende ao longo do curso, através do exercício de exploração, decisão e descobertas.

MÓDULO 3 - é constituído pelos eixos temáticos: Fundamentos Socioculturalpolítico-econômico do Processo Educativo; Espaços Educativos e Contexto Brasileiro; A Criança, o Espaço Educativo e Ação Docente, de Pesquisa e de Formação na Ação Docente. Os estudos desse módulo centram-se no caráter exploratório e nas decisões acerca das práticas que articulam a compreensão dos espaços educativos e a ação docente no contexto brasileiro. É o momento no qual se expressa a formulação e o encaminhamento de soluções para os problemas educacionais, na articulação do aprendizado e da pesquisa para a produção do conhecimento e para a prática pedagógica no compromisso ético, com a atuação do profissional. Os fundamen- 
tos epistemológicos e a compreensão a respeito da caracterização do contexto educativo facultam uma reflexão sobre o encaminhamento da pesquisa qualitativa e suas aplicações ao campo educacional.

MÓDULO 4 - contempla os eixos temáticos: A Criança, o Espaço Educativo e Ação Docente; Ação do Professor no Ensino Fundamental - Anos Iniciais; Instrumentação do Trabalho Pedagógico no Ensino Fundamental - Anos Iniciais e Pesquisa e Formação na Ação Docente. Este módulo fundamenta-se nos conhecimentos sobre a criança, os espaços educativos, a ação docente e suas especificidades, voltadas às interações realizadas na prática educativa dentro do espaço escolar. Propõe desenvolver a compreensão da instrumentalização do trabalho pedagógico, através de fundamentos e metodologias adequadas ao desempenho docente do professor, discutindo o desenvolvimento da criança e suas relações com o processo de ensino e aprendizagem. Centra-se na reflexão, análise e sugestões para superação de problemas educacionais, contemplando a dimensão do projeto pedagógico, a iniciação e aplicação de metodologias e materiais adequados às situações pedagógicas e a avaliação das propostas e processos pedagógicos.

MÓDULO 5 - é constituído pelos eixos temáticos: Ação do Professor no Ensino Fundamental - Anos Iniciais; Instrumentação do Trabalho Pedagógico no Ensino Fundamental - Anos Iniciais e Pesquisa e Formação na Ação Docente. Este módulo busca proporcionar ao professor a instrumentação da atividade pedagógica, através do trabalho com a fundamentação e as metodologias organizadas a partir das Diretrizes e dos Parâmetros Curriculares Nacionais para os Anos Iniciais. Contempla a reflexão suscitada pela pesquisa e os pressupostos necessários à formação para a ação docente. Desenrola-se a partir da reflexão sobre as vivências e as experiências já realizadas, considerando a análise, a formulação e o encaminhamento de soluções dos problemas educacionais relacionados à atuação do professor com as metodologias em sala de aula e à ação interdisciplinar do conhecimento humano no contexto escolar. Faculta discussões acerca do trabalho pedagógico e do cotidiano escolar, da formação e atuação do professor (co) responsável pela formação do ser humano integral, como cidadão.

MÓDULO 6 - É composto pelos eixos temáticos: Ação do Professor no Ensino Fundamental - Anos Iniciais; Instrumentação do Trabalho Pedagógico no Ensino Fundamental - Anos Iniciais; Pesquisa e Formação na Ação Docente. Este módulo tem como objetivo consolidar a articulação entre teoria e prática, inserindo o aluno em seu contexto social e cultural, e favorecer a compreensão do processo de construção do conhecimento, fundamentando sua prática e visando a formação de uma sociedade democrática.

\section{CONSIDERAÇÕES FINAIS}

No presente momento da história, tem havido uma corrida em busca da estruturação de cursos a distância, especialmente nas instituições públicas, com o apoio do 
governo federal. No entanto, várias instituições, públicas e particulares, já vêm desenvolvendo estudos na área desde a década de 90.

A experiência da UNOPAR apresentou uma proposta inovadora tanto no que diz respeito à aplicação da tecnologia à educação quanto ao projeto pedagógico do curso de formação de professores. Cabe ressaltar aqui que propostas inovadoras são alvo de críticas, muitas vezes por desconhecimento. Basta saber que vários desafios foram sendo enfrentados na implantação do curso, desde aqueles referentes aos aspectos legais, passando à articulação entre os aspectos pedagógicos e técnicos, e aos desafios de operacionalização da proposta pedagógica, até os de criação de uma cultura própria de estudo independente, fortemente presente na educação a distância, entre outros.

A legislação do início do milênio não proporcionava o amparo legal necessário para possibilitar respostas a todas as dúvidas referentes aos aspectos específicos, por exemplo, à expansão e à oferta de cursos. Havia inicialmente divergências até mesmo nas respostas às consultas do próprio MEC, dependendo do setor e das pessoas consultadas. Também outros fatores como transferências internas e externas, e documentação acadêmica causaram transtornos, no início do processo, e certa insegurança aos próprios alunos.

Além dos problemas de ordem externa, surgiram também problemas internos em razão do grande número de alunos, o que exigiu a criação de novas formas de gestão. Para atender a essas necessidades internas, criou-se, por exemplo, uma secretaria acadêmica específica de EAD, vinculada à secretaria acadêmica geral. Foi necessário, ainda, proceder a resoluções, a portarias, e a documentação de estágio e TCC, entre outros.

Outro desafio foi com relação à articulação entre a equipe técnica e a pedagógica. Houve cada vez mais necessidade de diálogo entre os profissionais das duas áreas para proporcionar uma perfeita afinação entre a linguagem técnica e a pedagógica, com profissionais técnicos dominando a linguagem pedagógica principalmente. Por necessidade de operacionalizar portfólio e outros recursos com características próprias, de criar mecanismos de interatividade e acompanhamento do aluno, e de elaborar um sistema de avaliação próprio, as plataformas comerciais utilizadas no início do curso foram substituídas por um sistema proprietário que vem sendo construído, avaliado e reconstruído no decorrer do processo, de acordo com as necessidades. Essa construção esbarrou, e ainda esbarra em um agravante que é a socialização (a distância) do uso das ferramentas e do sistema pelos envolvidos, por um lado, já que um sistema proprietário é sempre mais difícil de ser assimilado do que um já conhecido, existente no mercado. No entanto, por outro lado, sempre que uma etapa desafiadora é vencida, registra-se um ganho significativo para a proposta pedagógica, uma vez que o sistema proprietário se ajusta mais facilmente às exigências e características inerentes ao projeto como um todo. 
Registra-se ainda mais um desafio. Trata-se da dificuldade de operacionalização de uma proposta pedagógica de um curso a distância quando o referencial de formação dos envolvidos (alunos, professores, tutores, equipe pedagógica e técnica) foi essencialmente o ensino presencial. Implantar uma proposta inovadora em uma nova modalidade implica um ir e vir constante, refletir, discutir, rever posturas, modificar, desfazer e refazer. Assim, a necessidade de desconstruir e (re) construir determinadas atitudes e hábitos está presente nas atividades de todos. Um exemplo marcante disso é a elaboração das videoconferências pelos professores especialistas. Socializar o planejamento, fazer e refazer várias vezes, buscar e aceitar opiniões, usar e abusar da criatividade, facultar interatividade, abrir as portas da sala e da aula, tudo isso tornou-se atividade constante no cotidiano desses professores que tinham, até então, somente experiências em ensino presencial.

Da mesma forma, a criação da cultura do estudo a distância tem sido um outro desafio constante, para ser compreendida como parte de uma nova cultura, na qual professores e alunos se comunicam, mas separados fisicamente. Comprometer-se seriamente com um aluno sem face, mas com identidade é "novo" para o professor. Adquirir conhecimento comunicando com o professor por meio de tecnologias, adquirir autonomia, realizar atividades independentes, romper com a dependência do professor presencial, gerenciar o próprio tempo, superar a idéia de curso facilitador e aprender a aprender são funções novas colocadas aos alunos. A inserção em um novo universo causou e ainda causa a todos os envolvidos, ansiedade, medo e descrença, mas causa, também, curiosidade e desejo de conhecer.

Não são somente esses os desafios que se apresentam a um modelo de curso como o dessa envergadura, não são somente os fatores destacados que implicam nos aspectos citados. O curso tem-se apresentado, desde sua criação, como grande provocação a todos que com ele se envolveu de forma diferenciada.

As considerações aqui apresentadas constituem um pequeno recorte de todos os aspectos envolvidos no curso. Representam um novo caminho que se abre a nossa frente mostrando-nos um novo jeito de caminhar.

Porém, o Curso Normal Superior Presencial Conectado certamente tem contribuído para a construção da história da EAD no Brasil, rompendo barreiras sociais e apresentando um novo modelo de educação, que atende a uma demanda de regiões geográficas que o ensino presencial não consegue contemplar. Da mesma forma, estende a oferta de um ensino de qualidade a uma parcela significativa da população que até então não era atendida, contribuindo para a democratização do ensino no Brasil e tornando realidade um sonho de muitos cidadãos brasileiros. 


\section{REFERENCIAS BIBLIOGRÁFICAS}

Brasil, leis, decretos etc. (1996). Lei de Diretrizes e Bases da Educação Nacional (LDBEN); no 9394/96 [en línea]. Disponível

em:

http:// www.mec.gov.br/ legis/pdf/LDB. pdf [consulta 2004, 14 de dezembro].

Brasil, leis, decretos etc. (2001). Parecer 009/2001 do CNE/CP [en línea]. Disponível em: http:// www.mec.gov.br/ sesu/ftp/parece res/02101formprof.doc [consulta 2004, 29 de novembro].

Brasil. Ministério da Educação e Cultura (MEC). (2004). [Página oficial da Secretaria de Educação a Distância - SEED] [en línea]. Disponível em: http:// www.mec.gov.br/ seed/default.sht

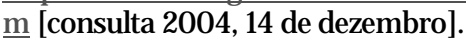

Endereco das autoras, para contato - Universidade do Norte do Paraná - PróReitoria de Educação a Distância - Centro de Pesquisa em EAD - Rua Tietê, 1208 - Vila Nova - CEP 86025-230 Londrina - Paraná - Brasil. Telefone: 0055 - 43 - 3371-7465; Fax: 0055 - 43 - 3371-7459.
Garrison, D.R. (1992). Critical thinking and self-directed learning in adults education: an analysis of responsibility and control issues. Adult Education Quarterly, 42 (3): 136-148.

Lobo Neto, F.J.S. (2004). Educação a Distância: Regulamentação, Condições de Êxito e Perspectivas, 1998 [en línea] Disponível em: http://www.intelecto.net/ ead textos/lo bo1.htm [consulta 2004, 29 de novembro].

Sammons, M. (2003). Exploring the new conception of teaching and learning in distance education, em Moore, G.M.; Anderson, W.G. Handbook of distance education. Mahwah : LEA, 387-397.

Universidade Norte do Paraná (UNOPAR). (2003) Projeto pedagógico do Curso Normal Superior - habilitação: anos iniciais do ensino fundamental. Londrina, 2003.

\section{PALABRAS CLAVE}

Formación de profesores, educación a distancia.

\section{KEY WORDS}

Profesors formation, distance education.

\section{PERFIL ACADÉMICO DE LAS AUTORAS}

Profa. Sandra Regina dos Reis Rampazzo - Mestre em Educação pela Universidade Estadual de Londrina (UEL); docente do Sistema de Ensino Presencial Conectado (SEPC) da Universidade Norte do Paraná (UNOPAR), encarregada do Setor de Planejamento e Avaliação da Aprendizagem no SEPC/UNOPAR e pesquisadora da linha de Gestão de Sistemas e Avaliação em EAD. 
Profa. Samira Fayez Kfouri - Mestre em Educação pela Universidade Estadual Paulista (UNESP), docente do SEPC/ UNOPAR, encarregada da Coordenação Pedagógica dos Cursos do SEPC/UNOPAR, pesquisadora da linha de Gestão de Sistemas e Avaliação em EAD; e docente da UEL.

Aparecida Theodora Gozo - Mestre em Educação pela Universidade Estadual de Ponta Grossa (UEPG), docente do SEPC/UNOPAR encarregada da Divisão de Tutoria e pesquisadora da linha de Gestão de Sistemas e Avaliação em EAD.

Dirección postal: $\quad$ Universidade Norte do Paraná

Londrina, Paraná, Brasil.

E-mail: sandra.rampazzo@unopar.br

samira.silva@unopar.br

cida.gozo@unopar.br

Fecha recepción del artículo: dd. mes. año

Fecha aceptación del artículo: dd. mes. año 